\title{
La influencia de los videojuegos de contenido apocalíptico en los adolescentes
}

\section{The influence of video games with apocalyptic content in adolescents}

\author{
LUIS NAVARRETE-CARDERO \\ Universidad de Sevilla \\ lnavarrete@us.es \\ Jose Luis MolinA-GonzÁlez \\ Universidad de Sevilla \\ molinarte@us.es
}

Recibido: 6 de octubre de 2013

Aprobado: 26 de noviembre de 2014

\section{Resumen}

El objetivo del presente trabajo es la disertación y el análisis de la influencia (sociológica, psicológica y cultural) que ejerce en los adolescentes el concepto de Apocalipsis. Convertido en una noción clave de la cultura visual, la denominada teoría del fin del mundo alcanza una de sus mayores expresiones en los videojuegos, posiblemente el divertimento preferido por los jóvenes en sus ratos de ocio. Los resultados obtenidos en esta investigación suponen un primer acercamiento a la materia a través de las muestras seleccionadas, dos institutos de la ciudad de Sevilla con localizaciones dispares y situaciones socioeconómicas divergentes. Para fortalecer el estudio comparativo se han incluido cuestiones vinculadas con el control parental, las principales plataformas de juego utilizadas por los encuestados o el número de horas de dedicación a este tipo de entretenimientos. Las conclusiones demuestran una irremediable atracción de nuestros jóvenes hacia universos apocalípticos, urdidos de manera inconsciente con el ocio y el entretenimiento como vías de escape de su cotidianidad.

Palabras clave: videojuegos, adolescentes, efectos de los Medios de Comunicación, estudiantes de secundaria, análisis del discurso.

Navarrete-Cardero, L., Molina-González, J.L. (2015): La influencia de los videojuegos de contenido apocalíptico en los adolescentes. Arte, Individuo y Sociedad, 27(2) 161-178

\begin{abstract}
The aim of this study is the dissertation and analysis of the influence (sociological, psychological and cultural) exerted on adolescents by the concept of Apocalypse. Become a key thought of visual culture, the called doomsday theory achieves one of its highest expressions in video games, possibly the favorite entertainment for young people in their leisure time. The results obtained in this research represent a first approach to the subject through the selected samples, two secondary schools from the city of Seville with disparate locations and divergent socioeconomic backgrounds. To reinforce the comparative study, we have included issues related to parental control, principal gaming platforms used by respondents or the number of hours dedicated to this type of entertainment. The conclusions demonstrate an irremediable attraction from our youth towards apocalyptic universes, plotter consciously with leisure and entertainment as escape from their routine of everyday life. Keywords: video games, adolescents, Mass Media effects, middle chool students, discourse analysis.
\end{abstract}


Sumario: 1. Introducción, 2. Materiales y métodos, 2.1. Ficha técnica del estudio, 3. Análisis de resultados y discusión, 3.1. Horas semanales dedicadas a los videojuegos, 3.2. Preferencia temática, 3.3. Número de jugadores, 3.4. Plataformas principales, 3.5. Apocalipsis. Aproximación estética, 3.6. Apocalipsis. Aproximación anímica, 3.7. Intereses temáticos dentro del apocalipsis, 3.8. Proyección y deseos sobre futuros juegos, 3.9. Motivaciones para jugar, 3.10. Control parental, 4. Conclusiones. Referencias.

Este artículo recoge resultados de la investigación Nuevas Tecnologías de la Información y Participación Ciudadana. Formas de Mediación Local y Desarrollo Comunitario de la Ciudadanía Digital financiada por Proyecto de Excelencia de la Junta de Andalucía, Consejería de Innovación, Ciencia y Empresas, Referencia: P08-SEJ-03680.

\section{Introducción}

En los límites del proyecto donde se incluye este trabajo, hemos tratado de acercarnos a las experiencias de uso de las nuevas tecnologías por parte de los adolescentes, un grupo fundamental para el desarrollo de una sociedad tecnológica que siempre aparece dispuesto a la utilización de novedosas prácticas digitales sobre las que deberían acentuarse las acciones educativas (Aguaded, J.I., 2012). El videojuego se ha configurado como el primer umbral de muchos de estos jóvenes en su relación con las tecnologías y un conformador importante de su particular cosmovisión. A diario, millones de escolares de todo el mundo se interconectan a través de sus consolas para compartir una aventura que la mayoría de las veces los adultos ignoran a pesar de su larga tradición en la esfera de los juegos (Lessard, J., 2103). Muchos de los universos frecuentados durante la experiencia lúdica ubican a los jugadores en espacios y tiempos de fantasía pero también los arrojan a situaciones dramáticas donde el mundo que conocen ha desaparecido debido a guerras, virus, ataques extraterrestres o hecatombes nucleares.

La hipótesis del fin del mundo puede encontrarse en todas las culturas y civilizaciones desde tiempos inmemoriales. En la tradición judeocristiana la escatología o ciencia de las realidades últimas engloba a la muerte, el juicio final, la gloria o el cielo, pero, además, da cuenta de las teorías apocalípticas que vaticinan el fin de la vida humana sobre el planeta Tierra (Potestà, G.L., 2010, p.323). Posiblemente, la conciencia narrativa del hombre, más allá de las peculiaridades intrínsecas de cada religión o cultura, es la clave de la influencia ejercida por el apocalipsis sobre la psique humana. En un ensayo clave para la Ciencia Cognitiva, el científico Mark Turner trata de desvelar los orígenes del pensamiento y del lenguaje asentando nuestros procesos cognitivos sobre la narración, es decir, fundamentando su estructura justamente sobre la existencia de un principio y un final en todo aquello que emprendemos (Turner, M., 1997). Las cualidades de esta mente temporal están íntimamente relacionadas con la naturaleza finita del ser humano, evidenciando una concepción del mundo erigida, a su imagen y semejanza, sobre la cuestión que más ha preocupado al hombre desde que lo es, su esencia mortal. Los mitos, cuentos y otras formas narrativas, le han servido tanto para canalizar sus miedos como para recordarle su irremediable final (Campbell, 1959, p.135). Todo parece indicar que el videojuego se ha convertido en el último vehículo de la idea del apocalipsis, tal vez descafeinada si la comparamos con otros discursos y con tiempos pasados, pero con resultados incontestables paralelos a la narrativización de este medio. 
Tal vez, la vigencia que las teorías apocalípticas poseen en la actualidad, a pesar de su carácter sucedáneo, se deben al período de entreguerras. La especulación moderna sobre el final de cualquier práctica intelectual y humana, según los cánones conocidos, tiene su inicio en los niveles más altos de la intelligentsia europea a mediados del siglo XX. Tales planteamientos son herederos de distintas concepciones filosóficas y sociológicas. El historiador Lutz Niethammer distingue tres variantes principales. Primero, la tesis de ascendencia nietzscheana sobre el agotamiento espiritual del repertorio de posibilidades heroicas; segundo, la imagen asociada a la obra de Max Weber de una sociedad en proceso de petrificación, convertida sólo en una máquina enorme; tercero, la idea de una entropía en el proceso de cambio de la civilización, según el esquema del historiador Henry Adams (Anderson, P., 1996, p.7). Con arreglo al estudio de Niethammer, esta corriente de pensamiento se urde en el área franco-germana, durante los años transcurridos entre el Frente Popular y el Plan Marshall, de la mano de pensadores alejados y no relacionados entre sí como Henri de Man, Arnold Gehln, Ernst Jünger, Walter Benjamín o Theodor Adorno. Todos compartieron la esperanza de un derrocamiento radical del orden establecido en Europa durante el período de entreguerras. Resulta evidente el pesimismo de este sentimiento y la fuerza ejercida sobre filósofos y estudiosos posteriores en forma de teorías negativas y destructivas que han extendido su efecto por doquier. A día de hoy, la conciencia heredada de ese terrible pasado, así como la certeza de nuestra incontrolable capacidad para acabar con el mundo en un abrir y cerrar de ojos, mantienen viva la llama de la teoría del fin.

La existencia en la actualidad de discursos críticos que reflexionen sobre la idea del fin del mundo, casos de obras pertenecientes a los escritores José Saramago (Ensayo sobre la ceguera, 1995) o Cormac McCarthy (The road, 2006), no es habitual, abundando el simple ejercicio espectacular. Grosso modo, la imaginería apocalíptica, antaño mostrada en los grabados de Goya, Durero o Callot, llega a nuestros jóvenes hoy día tamizada por el mundo del videojuego. Este hecho no sólo indica un cambio en los patrones del consumo cultural de nuestras sociedades o el nacimiento de nuevos objetos culturales, sino también la pérdida de fuerza de la vieja idea del apocalipsis, asentada ahora sobre un medio que, a pesar de sus deseos, aún no ha logrado la capacidad de análisis ni las posibilidades expresivas justas para trastocar su simple ejercicio de mostración en discurso cimentado sobre la reflexión. El apocalipsis como decorado. Como resultado de este proceso, los juegos de temática apocalíptica se nos aparecen como textos vacíos de cualquier intención crítica, ideológica o ética. Como hemos comprobado, el videojuego es la fuente principal que alimenta el imaginario de nuestros jóvenes, incapaces de señalar en muchos casos obras literarias o filmicas de temática apocalíptica pero confesos como grandes consumidores de videojuegos afines.

De otro modo, tenemos que pensar también que la estética implantada de manera sistematizada a propósito del apocalipsis en los videojuegos es deudora del concepto de lo sublime enunciado ya en la Grecia helenística por el crítico y retórico Pseudo-Longino y desarrollado extensamente por los románticos y especialmente por Edmund Burke en su A philosophical Enquiry into the Origin of our Ideas of the Sublime and the Beautiful (Vermeir, K. y Funk, D. M., 2012). Claramente, hablamos sólo del aspecto visual, momentáneo y efectista, porque la introspección filosófica que se realiza en los siglos XVIII y XIX se desvanece ante el obsolescencia consumista de los siglos XX y XXI en la denominada, por el sociólogo y filósofo polaco Zygmunt Bauman, modernidad 
líquida (2013). Lo sublime se expresa a través del arrebato sensitivo de atracción que produce en el individuo un espectáculo grandioso de dolor, caos y peligro, en el que frecuentemente la naturaleza tiene un papel decisivo. En este sentido, una buena parte de los diseñadores de videojuegos lanzan esta sublimidad a través de paisajes desolados y destruidos de importantes ciudades contemporáneas, al igual que lo haría Caspar David Friedrich en sus pinturas de ruinas góticas. A diferencia de la inmersión sensorial que podemos realizar a través de cuadros en cualquier museo romántico, los videojuegos traspasan al jugador a través de la experiencia (virtual), en la que el concepto de lo sublime alcanza su máximo nivel ya que, aunque no se sufra ningún peligro, los altos niveles de simulación escénica disponen al sujeto frente a una realidad paralela. El concepto de lo sublime también esconde un cierto "valor para poder medirnos con el todo-poder aparente de la naturaleza" (Kant, I., 1999, p. 204), y es por ello que los videojuegos de corte apocalíptico, encienden esa disposición a enfrentarse con un medio hostil que la mayoría de nosotros llevamos dentro, con la ventaja que supone tener un número de vidas infinitas en dicha ficción.

Por tanto, la recreación de un mundo apocalíptico se ha convertido en una clave esencial para el éxito de los juegos desarrollados por las grandes empresas. La meta de este estudio es descifrar ciertos hábitos sobre el consumo de videojuegos por parte de niños y jóvenes entre once y dieciséis años para esclarecer algunos resortes de su relación con esos mundos apocalípticos permutados en simples escenarios del juego. Más allá de cualquier posicionamiento ético o moral sobre estas prácticas, una óptica muy en boga (McKernan, B., 2103), la investigación sólo pretende desvelar si existe o no atracción por estas ficciones y qué emociones despiertan en los jugadores. Por otra parte, no parece irrelevante apuntar algunas consideraciones sobre la idea del apocalipsis en los juegos, oscilante entre el vacío significativo y el adiestramiento ideológico.

Los defensores de la primera opción apuntan que desde hace algunos años la imaginería de la catástrofe se ha institucionalizado como un recurso estilístico más de los discursos artísticos (Marchand, Y. y Meffre, R., 2010). En un proceso alejado de cualquier pretensión aleccionadora de cariz práctico o moral, la noción de apocalipsis se ha visto relegada, como sucede con otros artefactos de nuestra cultura, a simple bien de consumo desposeído de su valor de uso de antaño, conferido secularmente desde la política o desde la religión. En el imaginario global del hombre moderno, la idea del fin del mundo ha sido privada de cualquier voluntad temerosa o persuasiva, mostrándose exclusivamente como algo lúdico pero irrelevante, un objeto accesorio reducido a simple temática predilecta de la cultura del ocio. Así, el apocalipsis, convertido en categoría estética intrascendental, se utiliza fuera de sus límites primigenios para optar a sentidos no clausurados y, en consecuencia, vagamente significativos. Es decir, un ente alejado de la esfera aterradora de la representación de la finitud hoy conminado por la industria del entretenimiento al cultivo del pensamiento mítico de nuestros adolescentes gracias a lo espectacular y terrible de su estética. De este modo, a pesar de su mermada capacidad actual como elemento transformador de la sociedad, la idea del apocalipsis sigue ejerciendo una silenciosa autoridad cuyo éxito sólo puede radicar en su unión con resortes de nuestra humanidad inexplicables desde el ámbito de la ciencia.

Por el contrario, la otra tendencia considera a estos juegos firmes aliados para el adiestramiento ideológico de los jóvenes. Para ciertos autores, tras la vacuidad de los videojuegos de temática apocalíptica se aprecian graves implicaciones políticas. Con 
cierto ánimo parafrástico que recuerda a la teoría de la aguja hipodérmica, la especialista Anna Antrophy señala que la industria del videojuego, monopolizada, según la autora, por hombres blancos universitarios con estudios en ingeniería, sólo es el sedimento de dos ideas fundamentales de la cultura americana: la guerra y la fantasía. Tras las temáticas de estos videojuegos se esconde, por tanto, una pretendida adhesión de los jugadores a los planes de la política exterior pergeñados por esta ideología dominante (2012). La relación de ambos hechos, juegos e ideología dominante, ya había sido tratada por Marshall McLuhan en su obra La comprensión de los medios como las extensiones del hombre (1980). Para éste, los juegos no viven al margen de nuestra realidad en mundos separados sino que revelan el significado de nuestra cultura. Esto explicaría, por ejemplo, la preferencia entre los estadounidenses por el béisbol en detrimento del fútbol, un juego posicional y jerarquizado que evidencia el núcleo de la cultura norteamericana.

Finalmente, creemos necesaria una reflexión sobre el espacio en el que se inserta esta investigación en el campo de los videojuegos. Para ello nos vemos obligados a describir el actual panorama de los denominados Game Studies. A nuestro modo de entender, los diferentes estudios acometidos sobre el videojuego a lo largo de los últimos veinte años pueden aglutinarse bajo tres paradigmas conformados según los componentes que podemos hallar en la estructura general de toda teoría. De este modo, en cualquier construcción teórica encontramos, en primer lugar, un componente metafísico, es decir, la idea que tenemos sobre el objeto de estudio. Es la parte de la fundamentación conceptual y determina su comprensión. En segundo lugar hallamos un componente sistemático que atiende a los mandatos metodológicos obedecidos por la teoría. Por último, podemos vislumbrar un componente físico, referido a la adquisición de los datos empíricos, determinante en su valoración factual. Las teorías del videojuego se ciñen a un esquema similar: es comprobable en ellas la existencia de un núcleo de ideas que encuadran e intentan definir el objeto de estudio, una red de métodos aplicables al mismo y, finalmente, un conjunto de observaciones concretas que permiten verificarlas e interpretar su valor.

De la aplicación de esta taxonomía surgen, respectivamente, las teorías ontológicas, metodológicas y de campo. Las primeras, también llamadas teorías constitutivas o metafísicas, están conformadas por las investigaciones centradas en dirimir la naturaleza específica del videojuego. Su obligación es reflexionar sobre su esencia y clarificarlo como objeto de estudio. Como nos recuerda Casetti (1994: 22), este tipo de teorías suelen operar sobre la certidumbre, escogiendo, en alguna medida, la verdad como objetivo final. La pregunta que mejor ilustra su cometido es ¿qué son y qué define a los videojuegos? Las posibles respuestas pueden originarse desde diferentes aproximaciones, pero todas intentarán apoderarse de la verdad del medio, un hecho necesario para el avance de la teoría. Aquí cobra sentido la disputa entre ludólogos y narratólogos por dirimir la esencia del videojuego como medio de expresión.

La cuestión definitoria del segundo paradigma, que hemos denominado teorías metodológicas, no se preocupa por descubrir la esencia del videojuego, más bien pretende escrutar ¿desde qué punto de vista hay que observar al videojuego y cómo se capta desde esa perspectiva? Bajo este interrogante ya no se intenta discernir el estatus general del videojuego, en su lugar se resalta la aplicación de un método del que resultará una lectura determinada del objeto de estudio, bien desde una perspectiva comunicacional, sociológica, semiótica, etc. 
Por último, las teorías de campo se establecen cuando se intenta relacionar el objeto de estudio con una parcela de la realidad de interés para el investigador. Es decir, la relevancia aparece en la dimensión fenoménica del estudio. La pregunta clave que domina este tipo de investigaciones es ¿qué problemas puede iluminar el videojuego? Cuando esto ocurre, el investigador propone un campo de observación y delimita otro de preguntas y cuestiones. En nuestra opinión, existe un claro componente exploratorio en este tipo de trabajos, así como un trascendental papel de la hermenéutica en su constitución. El saber propuesto por las teorías de campo sólo es común a los investigadores que comparten las mismas preocupaciones. Pues bien, justamente en este último apartado de la teoría del videojuego cobra sentido el presente trabajo, un intento por esclarecer a través de su uso cuestiones que pertenecen a un campo de observación en apariencia alejado del videojuego.

Como orientación al lector interesado en esta triple vertiente que hemos señalado, podemos indicar algunas de las parcelas sobre las que se han volcado los esfuerzos investigadores de los Game Studies: el enfrentamiento clásico entre ludólogos y narratólogos marcó el inicio de los debates ontológicos sobre el medio, pero existen estudios posteriores que inclinan la palestra hacia nuevos conceptos como los de interacción versus narrativa o hacía propuestas que estudian el estado ficcional del videojuego a través del denominado Game World (Egenfeldt Nielsen, Heide Smith y Pajares Tosca, 2009). A este respecto pueden verse los trabajos, ya clásicos en el desarrollo de los game studies, de Lisbeth Klastrup (2003), Salen y Zimmerman (2004), Jesper Juul (2005), Jan Simons (2007) o James Newman (2013), así como los más recientes centrados en la dimensión lúdica, narrativa y enunciativa del medio, casos de Pérez Latorre (2012) o Antonio J. Gil (2013).

\section{Materiales y métodos}

Desprovistos de cualquier intención manifiesta por otorgar mayor relevancia a una u otra interpretación de la teoría del fin, se ha efectuado un estudio sobre jóvenes estudiantes con el deseo de evidenciar qué significado posee para ellos el concepto de apocalipsis. Lejos de sumir al encuestado en preguntas de carácter político o ideológico, sencillamente se ha elaborado un cuestionario abierto que ha servido para calibrar la naturaleza de su relación con la imagen del fin del mundo. De este cuestionario se ha inferido una serie de conclusiones que se explican en la discusión de los resultados y en la posterior conclusión.

La cuestión principal sobre la que se cierne esta investigación es la aproximación a las influencias que ocasiona sobre los adolescentes el consumo de un lenguaje audiovisual donde el concepto de apocalipsis aborda la mayoría de los formatos tecnológicos de ocio. Como se ha detallado en el apartado anterior, el estudio se ha centrado especialmente en los videojuegos. Bajo este hecho, los resultados se han fijado principalmente a través de un cuestionario realizado en dos Institutos de Enseñanza Secundaria de la ciudad de Sevilla. Desde dicha perspectiva, se plantea la necesidad de utilizar dos centros educativos con localización divergente y con un nivel socioeconómico distinto pero sin llegar a grandes extremos para conservar cierto equilibrio en la tendencia global de los resultados y un acceso garantizado de los alumno/as a las distintas plataformas de videojuegos. Tras una deliberación sobre aquellos que pudieran ser más adecuados y que 
a su vez permitieran el acceso, por su situación geográfica, a estudiantes de poblaciones cercanas, se optó por el Instituto Pablo Picasso, situado en el barrio de Alcosa (Distrito Este-Alcosa-Torreblanca), y el Instituto Carlos Haya, situado en el barrio de Tablada, (Distrito Triana-Los Remedios) como los candidatos idóneos para la toma de muestras.

La organización del cuestionario utilizado en la investigación mantiene una estructura abierta, para posibilitar la reflexión de los encuestados y evitar influencias conceptuales sobre los resultados. Dicha metodología ha permitido observar mayores matices en las opiniones resultantes y una mejor compresión sobre el estado de la cuestión. El formulario dispone de veinte preguntas entre las cuales doce de ellas tienen un perfil orientado de manera concreta hacia el concepto de apocalipsis y las ocho restantes desean completar aspectos que permitan una mejor compresión del grado de influencia. Algunos ejemplos son el número de horas semanales que se dedican a los videojuegos, el control parental sobre los mismos o el tipo de plataforma que se utiliza.

A partir de los cuestionarios, se desarrolla un modelo para la toma de muestras dividido en diez identificadores claves vinculados a los aspectos fundamentales del objeto de análisis. Dichos datos convierten las respuestas múltiples y heterogéneas en variables fijas que propician una mejor compresión de los resultados. Es importante señalar que conscientemente se ha desestimado la diferenciación de sexos para evitar un pronunciamiento sesgado sobre las muestras. No obstante, durante el tratamiento de algunos parámetros hemos considerado relevante destacar dicha distinción dentro de algún identificador clave debido a la divergencia manifestada entre distintos géneros.

\subsection{Ficha técnica del estudio}

Fecha de realización del trabajo de campo: Mayo-Junio 2013.

Metodología: Documentación bibliográfica y cuestionarios a estudiantes.

Instrumento de recogida de información: Registro de datos. Encuesta.

Datos de categorización: Instituto de Enseñanza Secundaria, nivel de estudios, situación geográfica, situación socioeconómica media de las familias.

Universo/Población: 267 alumnos de Institutos de Enseñanza Secundaria de la ciudad de Sevilla.

Muestra: Dos Centros. IES Carlos Haya e IES Pablo Picasso.

Tratamiento técnico y análisis: Manual e individualizado.

Identificadores clave:

1.- Horas semanales dedicadas a los videojuegos.

2.- Preferencia temática.

3.- Número de jugadores.

4.- Plataformas principales.

5.- Apocalipsis. Aproximación estética.

6.- Apocalipsis. Aproximación anímica.

7.- Intereses temáticos dentro del apocalipsis.

8.- Proyección y deseos sobre futuros videojuegos.

9.- Motivaciones para jugar.

10.- Control parental. 


\section{Análisis de los resultados y discusión}

Los resultados mostrados suponen un primer acercamiento a un estudio con pretensiones globalizadoras sobre la provincia de Sevilla. A pesar de contar para esta primera aproximación con muestras relativamente pequeñas, algunos datos, como veremos, parecen concluyentes. Se ha de tener presente que las encuestas contienen un gran número de preguntas no relacionadas en apariencia con el concepto de apocalipsis. Deliberadamente se han confeccionado de este modo con el deseo de definir un marco sociológico sobre determinadas pautas y comportamientos con relación al uso de los videojuegos por individuos pertenecientes a una franja de edad. A continuación, y manteniendo unas directrices paralelas al eje central del objeto de estudio, se detallan las consideraciones más relevantes de los cursos de $1^{\circ}$ de ESO de los citados Centros. Sin embargo, puede consultarse la evolución de los distintos cursos y grupos, así como el cuestionario inicial, en la siguiente URL [no disponible durante la revisión del artículo].

\subsection{Horas semanales dedicadas a los videojuegos}

Los resultados sobre esta cuestión apuntan a una distribución bastante equilibrada de las horas de juego. Puede observarse la existencia de jugadores ocasionales, otros que mantienen un nivel de juego medio y finalmente algunos que dedican gran parte de su tiempo a este tipo de entretenimiento. No obstante, los porcentajes más altos vienen definidos por aquellos que suelen jugar una media de entre una a cinco horas semanales. También se advierte en el análisis cruzado de los resultados que aquellos encuestados que dedican una mayor parte de su tiempo a los videojuegos suelen ser los que se decantan por estéticas apocalípticas con altas dosis de violencia explicita. Por otro lado, los porcentajes de jugadores que juegan más de diez horas disminuyen claramente conforme aumenta la edad del encuestado, resultando porcentajes muy bajos en alumnos de cuarto de ESO.

\begin{tabular}{|l|l|l|}
\hline IES Carlos Haya & \multicolumn{2}{l|}{ PRIMEROS 12/13 años } \\
\hline 65 alumnos & 19 & $29,23 \%$ \\
\hline CLAVE: Horas semanales dedicadas a los videojuegos \\
\hline Menos de 1 & 20 & $30,76 \%$ \\
\hline Entre 1 y 5 & 11 & $16,92 \%$ \\
\hline Entre 5 y 10 & 15 & $23,07 \%$ \\
\hline Más de 10 & &
\end{tabular}




\begin{tabular}{|l|l|l|}
\hline IES Pablo Picasso & \multicolumn{2}{l|}{ PRIMEROS 12/13 años } \\
\hline 53 alumnos & 9 & $16,98 \%$ \\
\hline CLAVE: Horas semanales dedicadas a los videojuegos \\
\hline Menos de 1 & 20 & $37,73 \%$ \\
\hline Entre 1 y 5 & 9 & $16,98 \%$ \\
\hline Entre 5 y 10 & 15 & $28,30 \%$ \\
\hline Más de 10 & & \\
\hline
\end{tabular}

\subsection{Preferencia temática}

En cuanto a la preferencia temática, se observa una clara inclinación por los videojuegos de un alto grado de violencia, donde los disparos son una constante. Por otra parte, los juegos de deporte también alcanzan un alto grado de aceptación y, en este sentido, queda reflejada la importancia del fútbol y los vehículos como primera opción, seguido por el baile. Las redes sociales también tienen su importancia en esta muestra. Aunque no es objeto de análisis en este estudio la diferenciación de sexo en los comportamientos lúdicos, consideramos importante destacar que las dos últimas temáticas preferentes, indicadas anteriormente, son referidas casi exclusivamente al género femenino. Parece relevante señalar que entre los jóvenes entre doce y trece años los videojuegos pertenecientes al género shooter, es decir, aquellos que mejor congenian con las temáticas apocalípticas, son los más jugados. Se aprecia un descenso de este tipo de juegos entre los cursos de tercero y cuarto, donde los videojuegos de deporte se imponen a los de disparos.

\begin{tabular}{|l|l|l|}
\hline IES Carlos Haya & \multicolumn{2}{l|}{ PRIMEROS 12/13 años } \\
\hline 65 alumnos & 26 & $40 \%$ \\
\hline CLAVE: Preferencia temática & \multicolumn{2}{l|}{} \\
\hline Disparos & 10 & $15,38 \%$ \\
\hline Plataforma & 15 & $23,07 \%$ \\
\hline Deportes & 2 & $3,07 \%$ \\
\hline Estrategia & 0 & $0 \%$ \\
\hline Simuladores & 9 & $13,84 \%$ \\
\hline Redes Sociales & 3 & $4,61 \%$ \\
\hline Juegos de mesa & 0 & $0 \%$ \\
\hline Otros & 0 &
\end{tabular}




\begin{tabular}{|c|c|c|}
\hline IES Pablo Picasso & \multicolumn{2}{|c|}{ PRIMEROS 12/13 años } \\
\hline \multicolumn{3}{|l|}{53 alumnos } \\
\hline \multicolumn{3}{|c|}{ CLAVE: Preferencia temática } \\
\hline Disparos & 21 & $39,62 \%$ \\
\hline Plataforma & 12 & $22,64 \%$ \\
\hline Deportes & 7 & $13,20 \%$ \\
\hline Estrategia & 3 & $5,66 \%$ \\
\hline Simuladores & 1 & $1,88 \%$ \\
\hline Redes Sociales & 9 & $16,98 \%$ \\
\hline Juegos de mesa & 0 & $0 \%$ \\
\hline Otros & 0 & $0 \%$ \\
\hline
\end{tabular}

\subsection{Número de jugadores}

Si bien a primera vista puede parecer que existe un importante equilibrio entre aquellos que prefieren jugar en solitario y aquellos que lo hacen en grupo, hay que subrayar la importancia del concepto online, que muchos encuestados han establecido como juego grupal. Sin embargo, es evidente que continúan jugando en solitario aunque conectados a través de internet. Según se desprende de datos posteriores, el juego online va unido en un alto porcentaje al uso de juegos de disparos y ficciones desarrolladas en mundos apocalípticos. Finalmente, los jugadores que juegan físicamente acompañados no suelen hacerlo online, utilizando el modo clásico de dos jugadores.

\begin{tabular}{|c|c|c|}
\hline \multicolumn{2}{|l|}{ IES Carlos Haya } & PRIMEROS 12/13 años \\
\hline \multicolumn{3}{|l|}{65 alumnos } \\
\hline \multicolumn{3}{|c|}{ CLAVE: Número de jugadores } \\
\hline 1 jugador & 28 & $43,07 \%$ \\
\hline 2 jugadores & 9 & $13,84 \%$ \\
\hline En grupo & 28 & $43,07 \%$ \\
\hline
\end{tabular}

\begin{tabular}{|c|c|c|}
\hline \multicolumn{2}{|c|}{ IES Pablo Picasso } & PRIMEROS 12/13 años \\
\hline \multicolumn{3}{|l|}{53 alumnos } \\
\hline \multicolumn{3}{|c|}{ CLAVE: Número de jugadores } \\
\hline 1 jugador & 26 & $49,05 \%$ \\
\hline 2 jugadores & 4 & $7,54 \%$ \\
\hline En grupo & 23 & $43,39 \%$ \\
\hline
\end{tabular}




\subsection{Plataformas principales}

Hay que destacar en este apartado la importancia de las consolas por encima de otro tipo de dispositivos para los jugadores encuestados. De ese modo el modelo de Sony parece superar al resto, seguido de cerca por Nintendo Wii, que ha sido especialmente seleccionada por aquellos que prefieren jugar en grupos (no online). No obstante, hay que señalar que una amplia mayoría de los encuestados han manifestado el uso de distintas plataformas según el momento y el tipo de juego.

\begin{tabular}{|c|c|c|}
\hline \multicolumn{2}{|l|}{ IES Carlos Haya } & PRIMEROS $12 / 13$ años \\
\hline \multicolumn{3}{|l|}{65 alumnos } \\
\hline \multicolumn{3}{|c|}{ CLAVE: Plataformas principales } \\
\hline Sony Playstation & 23 & $35,38 \%$ \\
\hline Microsoft Xbox & 7 & $10,76 \%$ \\
\hline Nintendo Wii & 12 & $18,46 \%$ \\
\hline Sony PS Vita & 1 & $1,53 \%$ \\
\hline Nintendo 3DS & 5 & $7,69 \%$ \\
\hline Sony PSP & 2 & $3,07 \%$ \\
\hline Móvil & 6 & $9,23 \%$ \\
\hline $\mathrm{PC} / \mathrm{Mac}$ & 9 & $13,84 \%$ \\
\hline
\end{tabular}

\begin{tabular}{|l|l|l|}
\hline IES Pablo Picasso & PRIMEROS 12/13 años \\
\hline 53 alumnos & \multicolumn{2}{|l|}{} \\
\hline CLAVE: Plataformas principales \\
\hline Sony Playstation & 19 & $35,84 \%$ \\
\hline Microsoft Xbox & 6 & $11,32 \%$ \\
\hline Nintendo Wii & 15 & $28,30 \%$ \\
\hline Sony PS Vita & 0 & $0 \%$ \\
\hline Nintendo 3DS & 2 & $3,77 \%$ \\
\hline Sony PSP & 1 & $1,88 \%$ \\
\hline Móvil & 6 & $11,32 \%$ \\
\hline PC/Mac & 4 & $7,54 \%$ \\
\hline
\end{tabular}

\subsection{Apocalipsis. Aproximación estética}

La primera de las preguntas vinculadas con el concepto de apocalipsis ha sido sorprendente. La gran mayoría de los encuestados manifiestan una clara atracción por este tipo de escenarios, aunque raramente encuentran belleza en los mismos. Se deduce una tendencia a relacionar la belleza con otro tipo de manifestaciones dentro 
de su franja de edad y cultura visual. La atracción por la fealdad de estos universos se urde, como se apreciará más adelante, con la vivencia de una aventura en un estado límite.

\begin{tabular}{|c|c|c|}
\hline \multicolumn{2}{|l|}{ IES Carlos Haya } & PRIMEROS 12/13 años \\
\hline \multicolumn{3}{|l|}{65 alumnos } \\
\hline \multicolumn{3}{|c|}{ CLAVE: Apocalipsis. Aproximación estética } \\
\hline Atracción & 40 & $61,53 \%$ \\
\hline Indiferencia & 1 & $1,53 \%$ \\
\hline Rechazo & 24 & $36,92 \%$ \\
\hline
\end{tabular}

\begin{tabular}{|c|c|c|}
\hline \multicolumn{2}{|l|}{ IES Pablo Picasso } & PRIMEROS 12/13 años \\
\hline \multicolumn{3}{|l|}{53 alumnos } \\
\hline \multicolumn{3}{|c|}{ CLAVE: Apocalipsis. Aproximación estética } \\
\hline Atracción & 30 & $56,60 \%$ \\
\hline Indiferencia & 6 & $11,32 \%$ \\
\hline Rechazo & 17 & $32,07 \%$ \\
\hline
\end{tabular}

\subsection{Apocalipsis. Aproximación anímica}

Aunque una gran mayoría de los encuestados no han sabido expresar exactamente sus sentimientos y emociones al utilizar videojuegos de temática apocalíptica, un buen número de ellos ha manifestado cierta tensión, ansiedad y miedo, aunque descrito con otro tipo de lenguaje. Muy pocos han mostrado indiferencia o aburrimiento con relación a este tipo de juegos. Es destacable el uso del concepto de tristeza y depresión en algunas de las muestras.

\begin{tabular}{|l|l|l|}
\hline \multicolumn{2}{|l|}{ IES Carlos Haya } & PRIMEROS 12/13 años \\
\hline 65 alumnos & \multicolumn{2}{|l|}{} \\
\hline CLAVE: Apocalipsis. Aproximación anímica \\
\hline Miedo & 14 & $21,53 \%$ \\
\hline Ansiedad & 10 & $15,38 \%$ \\
\hline Relajación & 1 & $1,53 \%$ \\
\hline Aburrimiento & 2 & $3,07 \%$ \\
\hline Otros & 38 & $58,46 \%$ \\
\hline
\end{tabular}




\begin{tabular}{|l|l|l|}
\hline \multicolumn{2}{|l|}{ IES Pablo Picasso } & PRIMEROS 12/13 años \\
\hline 53 alumnos & \multicolumn{2}{|l|}{} \\
\hline CLAVE: Apocalipsis. Aproximación anímica \\
\hline Miedo & 14 & $26,41 \%$ \\
\hline Ansiedad & 3 & $5,66 \%$ \\
\hline Relajación & 1 & $1,88 \%$ \\
\hline Aburrimiento & 1 & $1,88 \%$ \\
\hline Otros & 34 & $64,15 \%$ \\
\hline
\end{tabular}

\subsection{Intereses temáticos dentro del apocalipsis}

La respuesta a esta pregunta ha sido muy clarificadora, ya que se deduce una clara influencia del tipo de películas que están de actualidad en las carteleras más comerciales. Por otra parte, la importancia de marketing de algunos videojuegos se hace notar en la elección de las guerras entre países como una de las opciones más destacadas, especialmente en el instituto donde posiblemente las familias cuenten con un nivel de renta superior. No resulta extraño que los videojuegos más vendidos por las grandes corporaciones se desarrollen justamente en escenarios bélicos

\begin{tabular}{|l|l|l|}
\hline \multicolumn{2}{|l|}{ IES Carlos Haya } & PRIMEROS 12/13 años \\
\hline 65 alumnos & \multicolumn{2}{|l|}{} \\
\hline CLAVE: Intereses temáticos dentro del apocalipsis \\
\hline Invasión extraterrestres & 4 & $6,15 \%$ \\
\hline Hecatombe nuclear & 7 & $10,76 \%$ \\
\hline Desastres naturales & 9 & $13,84 \%$ \\
\hline Virus y contagios & 22 & $33,84 \%$ \\
\hline Guerras entre países & 23 & $35,38 \%$ \\
\hline
\end{tabular}

\begin{tabular}{|l|l|l|}
\hline \multicolumn{2}{|l|}{ IES Pablo Picasso } & PRIMEROS 12/13 años \\
\hline 53 alumnos & \multicolumn{2}{|l|}{} \\
\hline CLAVE: Intereses temáticos dentro del apocalipsis \\
\hline Invasión extraterrestres & 10 & $18,86 \%$ \\
\hline Hecatombe nuclear & 9 & $16,98 \%$ \\
\hline Desastres naturales & 9 & $16,98 \%$ \\
\hline Virus y contagios & 17 & $32,07 \%$ \\
\hline Guerras entre países & 8 & $15,09 \%$ \\
\hline
\end{tabular}




\subsection{Proyección y deseos sobre futuros videojuegos}

En respuesta a dicha cuestión existe un amplio interés hacia los videojuegos de disparos y plataformas, donde transcurre una aventura lineal. Los deportes y las redes sociales también mantienen un interés general. Sin embargo, los juegos de estrategia, los simuladores y los juegos de mesa son claramente rechazados entre las preferencias generales de los encuestados. Los porcentajes de los juegos esperados son muy similares a los de los juegos jugados, es decir, se observa una tendencia conservadora y poco dada a la vivencia de nuevas experiencias. Los jugadores juegan una y otra vez el mismo modelo de juegos.

\begin{tabular}{|l|l|l|}
\hline \multicolumn{2}{|l|}{ IES Carlos Haya } & PRIMEROS 12/13 años \\
\hline 65 alumnos & 23 & \\
\hline \multicolumn{2}{|l|}{ CLAVE: Proyección y deseos sobre futuros videojuegos } \\
\hline Disparos & 14 & $35,38 \%$ \\
\hline Plataforma & 15 & $21,53 \%$ \\
\hline Deportes & 0 & $23,07 \%$ \\
\hline Estrategia & 0 & $0 \%$ \\
\hline Simuladores & 13 & $0 \%$ \\
\hline Redes Sociales & 0 & $20 \%$ \\
\hline Juegos de mesa & 0 & $0 \%$ \\
\hline Otros & & $0 \%$ \\
\hline
\end{tabular}

\begin{tabular}{|l|l|l|}
\hline \multicolumn{2}{|l|}{ IES Pablo Picasso } & PRIMEROS 12/13 años \\
\hline 53 alumnos & 17 & $32,07 \%$ \\
\hline \multicolumn{2}{|l|}{ CLAVE: Proyección y deseos sobre futuros videojuegos } \\
\hline Disparos & 14 & $26,41 \%$ \\
\hline Plataforma & 9 & $16,98 \%$ \\
\hline Deportes & 1 & $1,88 \%$ \\
\hline Estrategia & 1 & $1,88 \%$ \\
\hline Simuladores & 10 & $18,86 \%$ \\
\hline Redes Sociales & 0 & $0 \%$ \\
\hline Juegos de mesa & 1 & $1,88 \%$ \\
\hline Otros & & \\
\hline
\end{tabular}




\subsection{Motivaciones para jugar}

En este sentido, la diversión ocupa el primer lugar entre las posibles opciones. Sin embargo, es significativo entre las respuestas recogidas, la amplia sensación de rutina que manifiestan personas de estas edades, quienes deciden jugar a videojuegos por dicho motivo. De todos modos, la gran mayoría juega por simple diversión, concepto que aglutinaría un mayor porcentaje si entendemos que Vivir una aventura o Descansar de la rutina son conceptos incluidos en éste.

\begin{tabular}{|c|c|c|}
\hline IES Carlos Haya & \multicolumn{2}{|c|}{ PRIMEROS 12/13 años } \\
\hline \multicolumn{3}{|l|}{65 alumnos } \\
\hline \multicolumn{3}{|c|}{ CLAVE: Motivaciones para jugar } \\
\hline Descansar de la rutina & 12 & $18,46 \%$ \\
\hline Vivir una aventura & 7 & $10,76 \%$ \\
\hline Diversión & 35 & $53,84 \%$ \\
\hline Conocer nuevas realidades & 4 & $6,15 \%$ \\
\hline Otros & 7 & $10,76 \%$ \\
\hline
\end{tabular}

\begin{tabular}{|l|l|l|}
\hline IES Pablo Picasso & \multicolumn{2}{l|}{ PRIMEROS 12/13 años } \\
\hline 53 alumnos \\
\hline \multicolumn{4}{|l|}{ CLAVE: Motivaciones para jugar } \\
\hline Descansar de la rutina & 7 & $13,20 \%$ \\
\hline Vivir una aventura & 13 & $24,52 \%$ \\
\hline Diversión & 24 & $45,28 \%$ \\
\hline Conocer nuevas realidades & 4 & $7,54 \%$ \\
\hline Otros & 5 & $9,43 \%$ \\
\hline
\end{tabular}

\subsection{Control parental}

Esta pregunta muestra importantes resultados desde el punto de vista sociológico. Si bien muchos encuestados declaran que sus padres conocen el tipo de videojuegos con los que se divierten, la gran mayoría manifiestan que disponen de juegos con un perfil más adulto al recomendado para su edad. También hay que señalar como en el instituto donde se presupone un mayor nivel de rentas familiares existe un mayor control parental. La variable Control parcial se ha definido justamente entre aquellos jugadores que sus padres conocen sus juegos pero desconocen su código PEGI. 


\begin{tabular}{|c|c|c|}
\hline \multicolumn{2}{|l|}{ IES Carlos Haya } & PRIMEROS 12/13 años \\
\hline \multicolumn{3}{|l|}{65 alumnos } \\
\hline \multicolumn{3}{|c|}{ CLAVE: Control parental } \\
\hline Existe control & 26 & $40 \%$ \\
\hline Control parcial & 32 & $49,23 \%$ \\
\hline Sin control & 7 & $10,76 \%$ \\
\hline \multicolumn{2}{|c|}{ IES Pablo Picasso } & PRIMEROS 12/13 años \\
\hline \multicolumn{3}{|l|}{53 alumnos } \\
\hline \multicolumn{3}{|c|}{ CLAVE: Control parental } \\
\hline Existe control & 16 & $30,18 \%$ \\
\hline Control parcial & 26 & $49,05 \%$ \\
\hline Sin control & 11 & $20,75 \%$ \\
\hline
\end{tabular}

\section{Conclusiones}

De los resultados comentados podemos extraer algunas conclusiones. Son las siguientes:

1.- Aunque la encuesta no ha sido elaborada para discernir entre los tipos de juegos jugados por los jugadores casuales y los jugadores empedernidos, podemos concluir que un gran número de jóvenes juega a videojuegos de contenido apocalíptico desarrollados en escenarios bélicos, principalmente los títulos Call of Duty o Battlefield en cualquiera de sus versiones. Por otra parte, son los mismos juegos que esperan comprar en el futuro.

2.- El juego online se muestra como una tendencia en alza que se impone al juego acompañado. Aunque es una nueva modalidad de juego en solitario, los jóvenes no lo consideran como tal pues lo hacen conectados a través de servidores donde contactan con amigos. Los juegos bélicos anteriormente citados poseen los modos de juego online más poderosos jamás diseñados. De hecho, gran parte de la controversia sobre las nuevas generaciones de consolas se ha centrado en definir el modelo de venta de los juegos de segunda mano y su acceso a la modalidad online. Dicho de otro modo, el juego online se prefigura como la nueva tarta del mercado por la que luchan los grandes estudios y las distribuidoras de videojuegos.

3.- Como puede comprobarse en la lectura global de las encuestas que presentamos en la URL [no disponible durante la revisión del artículo], resulta muy llamativa la incapacidad de gran parte de los adolescentes para señalar ficciones noveladas o filmicas que traten el tema del apocalipsis. De todos es sabido que la cultura escrita ha sufrido un desplazamiento hacia el universo audiovisual; pero este descentramiento es tan drástico que afecta incluso al cine, uno de sus miembros más insignes, que ha visto usurpado por el videojuego su lugar hegemónico como maquina fabuladora predilecta de las generaciones actuales. 
4.- Los jugadores juegan mayoritariamente por diversión. Pero resulta curioso que para divertirse recurran a mundos no bellos por los que sienten una gran atracción. Es justamente en estos donde pueden vivir una aventura que les saca de su rutina habitual. Nuevamente, como ocurre con gran parte de la ficción literaria o cinematográfica, el videojuego se configura como un complemento de cierta carencia sentida en la realidad. El juego es una indemnización por lo no vivido, una fábula en la que nos sentimos desterrados de nuestra auténtica existencia.

5.- En este sentido, resultan muy clarificadoras las emociones sentidas por los jugadores, oscilantes entre el miedo y la ansiedad. Situaciones excitantes ajenas a su vida cotidiana asociadas claramente a la diversión. La preferencia por la fealdad del mundo ficticio en lugar de jugar y experimentar en uno bello y sosegado, habla claramente de un componente mágico e inasible en los videojuegos que conecta con nuestras pulsiones más básicas.

6.- La libertad de los jóvenes para jugar a juegos con un código PEGI inapropiado indica un débil control parental sobre las actividades lúdicas de sus hijos. El hecho de que muchos padres sepan que juegan a juegos para adultos pero no hagan nada para evitarlo puede tener múltiples interpretaciones pero todas aventuradas. Posiblemente, la consideración de los videojuegos como actividad inocua e inofensiva esté en la raíz de este comportamiento, más allá de la demonización del juego por algunos sectores de la sociedad.

7.- Finalmente, las razones de la fascinación de nuestros jóvenes por el apocalipsis no pueden explicarse a través del trabajo presentado. Alcanzar la comprensión de este fenómeno es una tarea mucho más compleja que demostrar su simple atracción; para ello sería necesario un trabajo interdisciplinar que aglutinase tanto el estudio del presente como del pasado, así como un minucioso análisis de la idea de futuro que hemos construido para estos adolescentes.

\section{Referencias}

Aguaded, J.I. (2012). La competencia mediática, una acción educativa inaplazable. Comunicar, 39, pp. 07-08. Doi: 10.3916/C39-2012-01-01.

Anderson, P. (1996). Los fines de la historia. Barcelona: Anagrama.

Antrophy A. (2012). Rise of the videogame zinisters. Nueva York: Seven Stories Press.

Bauman, Zygmunt (2013). La cultura en el mundo de la modernidad líquida. México: Fondo de Cultura Económica.

Campbell, J. (1959). El héroe de Las mil caras. Psicoanálisis del mito. México: Fondo de Cultura Económica.

Casetti, F. (1994). Teorías del cine. Madrid: Cátedra.

Egenfeldt, S., Heide, J., Pajares, S. (2009). Understanding Videogames. The Essential Introduction. New York: Routledge.

Gil, Antonio J. (2012). + NARRATIVA (S). Intermediaciones novela, cine, cómic y videojuego en el ámbito hispánico. Ediciones Universidad de Salamanca: Salamanca.

Juul, J. (2005). Half-Real: Video Games Between Real Rules and Fictional Worlds. The MIT Press: Cambridge. 
Kant, I. (1999). Crítica del juicio. Madrid: Espasa Calpe.

Klastrup, L. (2003). Towards a Poetics of Virtual Worlds. IT University of Copenhagen. Copenhagen.

Lessard, J. (2013). Adventure Before Adventure Games: A New Look at Crowther and Woods's Seminal Program. Games and Culture, May 2013; vol. 8: pp. 119135. Doi: $10.1177 / 1555412012473364$.

Marchand Y., Meffre R. (2010). The ruins of Detroit. Gottingen/París: Steidl/ Edition7L.

McKernan, B. (2013). The Morality of Play: Video Game Coverage in The New York Times From 1980 to 2010. Games and Culture, vol. 8: pp. 307-329. Doi: $10.1177 / 1555412013493133$.

McLuhan, M. (1980). La comprensión de los medios como las extensiones del hombre. México: Diana.

Newman, J. (2013). Videogames. New York: Routledge.

Pérez Latorre, O. (2012). El lenguaje videolúdico. Análisis de la significación del videojuego. Barcelona: Laertes.

Potestà G. L. (2010). El tiempo del Apocalipsis. Vida de Joaquín de Fiore. Madrid: Editorial Trotta.

Salen, K. y Zimmerman, E. (2004). Rules of Play. Game Design Fundamentals. The MIT Press: Londres.

Zimmerman, E (2004). "Narrative, interactivity, play, and games: four naughty concepts in need of discipline." En First Person: New Media as Story, Performance, and Game. Ed. Noah Wardrip-Fruin \& Pat Harrigan. The MIT Press: Cambridge.

Simon, J. (2007). Narrative, Games, and Theory, Game Studies, 7, 1. [http://gamestudies. org/0701/articles/simons]. [Fecha de consulta: 8 de enero de 2014].

Turner M. (1997). The Literary Mind: The Origins of Thought and Language. Nueva York: Oxford University Press.

Vermeir, K. y Funk D. M. (eds.) (2012). The Science of Sensibility: Reading Burke's Philosophical Enquiry. Dordrecht: Springer Science + Business Media B.V. 